\title{
Extratos, decoctos e óleos essenciais de plantas medicinais e aromáticas na inibição de Glomerella cingulata e Colletotrichum gloeosporioides de frutos de goiaba
}

\author{
Extracts, decoctions and essential oils of medicinal and aromatic plants in the inhibition of \\ Colletotrichum gloeosporioides and Glomerella cingulata isolates from guava fruits
}

\author{
Luciane Cristina Rozwalka ${ }^{{ }^{*}}$ Maria Lúcia Rosa Zaksevskas Da Costa Lima ${ }^{I I}$ \\ Louise Larissa May de Mio" ${ }^{\mathrm{II}}$ Tomoe Nakashima ${ }^{\mathrm{IV}}$
}

\section{RESUMO}

A principal doença da goiaba (Psidium guajava L.), após a colheita, é a antracnose, causada por Glomerella cingulata e Colletotrichum gloeosporioides. Estes patógenos $e$ o resíduo de fungicidas em frutos são considerados os principais problemas para a exportaçãodesta fruta. Neste trabalho, foi avaliado o efeito fungitóxico de extratos, decoctos e óleos essenciais de plantas medicinais e aromáticas, no crescimento micelial dos patógenos, in vitro, recomendados como alternativa para o controle químico em pós-colheita. Os extratos aquosos a $10 \%$ e os decoctos (subprodutos da hidrodestilação) foram adicionados em BDA, autoclavados $e$ distribuídos em placas de Petri. Os óleos essenciais foram adicionados em três pontos eqüidistantes nas placas de Petri contendo BDA. Discos dos isolados foram repicados para o centro das placas de Petri. O efeito fungitóxico foi avaliado medindo-se o diâmetro das colônias, quando na testemunha ou em qualquer tratamento os patógenos atingiram a borda da placa. $O$ extrato aquoso e o óleo essencial de cravo-daÍndia inibiram em $100 \%$ o crescimento de G. cingulata e $\boldsymbol{C}$. gloeosporioides, sendo este último totalmente inibido pelo óleo essencial de capim-limão. Os decoctos de alecrim, gengibre, calêndula e laranja (Citrus sinensis) apresentaram potencial de inibição sobre os isolados dos patógenos. No controle de $\boldsymbol{C}$. gloeosporioides, destacaram-se também os decoctos de marcela, camomila e tagetes. A inibição total ou parcial do crescimento micelial de Glomerella cingulata e Colletotrichum gloeosporioides, in vitro, evidenciou a existência de compostos biologicamente ativos, com efeito fungitóxico nos extratos, decoctos e óleos essenciais de plantas medicinais e aromáticas. Isto indica uma aplicação potencial destes produtos no controle alternativo da antracnose em frutos de goiabeira.

Palavras-chave: antracnose, crescimento micelial, controle alternativo, Psidium guajava.

\begin{abstract}
The main disease of the guava (Psidium guajava L.), after harvesting, is anthracnose, caused by Glomerella cingulata and Colletotrichum gloeosporioides. This pathogen and chemical residues of fungicides in fruits are considered the mains problems for exportation. In this work was evaluated the fungitoxic effect of extracts, decoctions and essential oils of medicinal and aromatic plants in the mycelium growth of the pathogens, in vitro, to be recommended as an alternative to chemical control in postharvest. To prepare the aquous extracts a $10 \%$ and the decoctions (sub-products of hydrodistillation) were added in PDA medium, autoclaved and distributed into Petri dishes. The essential oils were added in three equidistant points by Petri dishes contening PDA medium. Discs of the isolates of the pathogen were placed on the center of the Petri dishes. The fungitoxic effect was evaluated by measuring the diameter of the colonies when the pathogens or any other treatment reached the border of the Petri dishes. The aquous extract and the essential oil from the clove inhibit in $100 \%$ of G. cingulata and C. gloeosporioides growth, and the last one was totally inhibited by the essential oil of the lemon grass. The decoctions of rosemary, ginger, calendula, orange (Citrus sinensis) showed inhibition potencial to control both isolates of the pathogen. In the control of $\boldsymbol{C}$. gloeosporioides also had good results the decoctions of mayweed, chamomile and tagetes. The total or partial mycelium growth inhibition of the Glomerella cingulata e Colletotrichum gloeosporioides showed the existence of compounds biologically actives with fungitoxic effect, in the extracts, decoctions and essential oils of medicinal and aromatic plants. This indicated a potential application of this products as an alternative to control anthracnose in guavas fruits.
\end{abstract}

Key words: anthracnose, mycelium growth, alternative control, Psidium guajava.

\footnotetext{
IPrograma de Pós-graduação em Agronomia, Produção Vegetal, Universidade Federal do Paraná (UFPR), Curitiba, PR, Brasil. Email: luciane.rozwalka@gmail.com. *Autor para correspondência.

IDepartamento de Fitotecnia e Fitossanitarismo, Setor de Ciências Agrárias, UFPR, Curitiba, PR, Brasil. "In memorian”.

IIIDepartamento de Fitotecnia e Fitossanitarismo, Setor de Ciências Agrárias, UFPR, Curitiba, PR, Brasil.

${ }^{\text {IV }}$ Departamento de Farmácia, Setor de Ciências da Saúde, UFPR, Curitiba, PR, Brasil.
} 


\section{INTRODUÇÃO}

O Brasil é um país marginal no comércio mundial de frutas frescas, sendo que, do total produzido até 2002, apenas 1\% destinava-se à exportação (Europa $63 \%$ e Mercosul 18\%). Sob o enfoque de exigências internacionais de um mercado importador concentrado e exigente, protegido por barreiras fitossanitárias, as frutas brasileiras de clima tropical são pouco conhecidas e apresentam baixo padrão de qualidade, devido ao inadequado uso de agrotóxicos e à tecnologia deficiente de pós-colheita (ALMEIDA, 2002). Mercados importadores realizam o controle e a fiscalização permanente de toda a cadeia produtiva no país exportador, através de programas e legislações específicas, tornando a qualidade certificada de frutas uma exigência (NAKA, 2001), principalmente da Comunidade Européia, rigorosa em requisitos de qualidade e sustentabilidade, enfatizando a proteção do meio ambiente, a segurança alimentar, as condições de trabalho, saúde humana e viabilidade econômica, que se consolidam pela Produção Integrada de Frutas (IOBC/WPRS, 1999).

Assim, tornou-se imprescindível a realização de pesquisas com produtos alternativos químicos para o controle de doenças, principalmente, em pós-colheita. Para a inserção e o incremento da participação do Brasil no mercado externo, oportunidades são geradas com o aumento da demanda no período de entressafra dos países do Hemisfério Norte e o surgimento de nichos de mercado para a fruticultura tropical (mamão, manga, e laranja) e espécies exóticas como maracujá e goiaba (SEBRAEMG, 2001).

A maior parte da produção de goiaba é consumida como fruta fresca e o restante processado sob as formas de goiabada (doces em massas), geléia, bala, sucos, polpa, vinho, néctar, sorvete, base para xaropes e bebidas, fruta seca e conservas (CARVALHO, 1994; SALUNKHE \& KADAM, 1995).

A principal doença, em pós-colheita, da goiaba é a antracnose, ou mancha-chocolate, causada pelo fungo Colletotrichum gloeosporioides (Penz) Arx (=Gloeosporium psidii Delacr.), cuja forma sexuada corresponde a Glomerella cingulata (Ston.) Spauld \& Schrenk (FRUPEX, 1996). Manchas de antracnose em qualquer número ou intensidade são classificadas como podridão (dano patológico que implica qualquer grau de decomposição, desintegração ou fermentação dos tecidos) e defeito grave de acordo com normas de classificação, ocasionando inevitavelmente a desclassificação do lote para comercialização; não sendo permitida a reclassificação quando a podridão for acima de 10\% (CEAGESP, 2000).
A alta incidência de antracnose, observada em locais destinados à comercialização de frutas e hortaliças, incitou preocupação em relação às perdas econômicas significativas pela redução do período de comercialização, desclassificação e descarte de frutos, ainda que tratamentos fitossanitários de pré ou póscolheita tenham sido realizados. O controle químico com a utilização de fungicidas, considerado em muitos casos como a única medida eficiente e economicamente viável (KIMATI, 1995), em alguns casos vem ocorrendo de forma exacerbada e indiscriminada, oferecendo risco à saúde da população e danos irreparáveis ao meio ambiente, seja pela não-observância de dosagens e período de carência, seja pelo uso de princípios ativos não registrados para a cultura.

Trabalhos desenvolvidos com extrato bruto ou óleo essencial de plantas medicinais e aromáticas, obtidos a partir da flora nativa, têm indicado o potencial de controle de fitopatógenos, tanto pela ação fungitóxica direta, inibindo o crescimento micelial e a germinação de esporos, quanto pela indução de fitoalexinas, indicando a presença de composto(s) com característica(s) de elicitor(es) (STANGARLIN et al., 1999; SCHWAN-ESTRADA et al., 2000; SALGADO, 2003; CUNICO et al., 2004; BONALDO et al., 2004; BASTOS \& ALBUQUERQUE, 2004). Visando ao controle de Colletotrichum sp., várias pesquisas estão sendo realizadas com produtos alternativos; entretanto, para Colletotrichum gloeosporioides e Glomerella cingulata em goiabeira, inexistem relatos.

Neste contexto, o presente trabalho teve como objetivo geral a avaliação do efeito fungitóxico de plantas medicinais e aromáticas, na forma de extratos, óleos essenciais e decoctos, no crescimento micelial de Glomerella cingulata (Colletotrichum gloeosporioides), agente causal da antracnose em frutos de goiabeira (Psidium guajava L.), in vitro.

\section{MATERIAL E MÉTODOS}

Para a obtenção de isolados do patógeno, frutos verdes de goiabeira (Psidium guajava L.), cultivares "Iwao" ou "Carlópolis” (polpa branca) e "Paluma” (polpa vermelha), adquiridos na Central de Abastecimento de Curitiba (CEASA-PR), foram acondicionados individualmente em câmaras úmidas, mantidas no ambiente à temperatura média de $22^{\circ} \mathrm{C}$, até o aparecimento de lesões e estruturas fúngicas. Em condições assépticas, por meio de isolamento direto, estruturas fúngicas caracterizadas por uma massa de esporos de coloração alaranjada e micélio das lesões maiores foram transferidas para placas de Petri (90mm) contendo o meio de cultura ágar-água (AA) a 2\%, 
mantidas em estufa a $28 \pm 2{ }^{\circ} \mathrm{C}$ no escuro. Observado o crescimento micelial, discos de $5 \mathrm{~mm}$ de diâmetro dos isolados foram repicados para o meio de cultura BDA (batata-dextrose-ágar) e incubados em estufa a $28 \pm$ $2^{\circ} \mathrm{C}$, no escuro.

Os isolados de Glomerella cingulata e Colletotrichum gloeosporioides foram obtidos de frutos de goiabeira de polpa branca e vermelha e identificados por meio de análise de estruturas via microscopia de luz. Para avaliar a patogenicidade dos isolados de Glomerella cingulata e Colletotrichum gloeosporioides, frutos de polpa branca e vermelha foram inoculados por meio de ferimentos obtidos com estilete contendo micélio dos patógenos; a seguir, os frutos foram acondicionados em câmara úmida, em temperatura ambiente de aproximadamente $25^{\circ} \mathrm{C}$. Para Glomerella cingulata, foi avaliada a especificidade, inoculando-se, da mesma forma como descrito acima, frutos de goiabeira e macieira. A presença de sintomas característicos dos patógenos, nos ferimentos, foi o parâmetro utilizado para as avaliações.

As plantas medicinais e aromáticas selecionadas para a avaliação do efeito fungitóxico sobre os fitopatógenos incluíram: alecrim (Rosmarinus officinalis), alfavaca/manjericão(Ocimum basilicum), bardana (Articum Iappa, A. minus), calêndula (Calendula officcinalis), camomila (Chamomila recutita), capim-limão (Cymbopogon citratus), cavalinha (Equisetum sp.), espinheira-santa (Maytenus ilicifolia), funcho (Foeniculum vulgare), gengibre (Zingiber officinale), hortelã (Mentha piperita), lípia (Lippia alba), marcela (Achryrocline satureoides), quebra-pedra (Phyllanthus sp.), sabugueiro (Sambucus nigra), tansagem (Pantago australis, $\boldsymbol{P}$. major) e tagetes (Tagetes minuta), citadas em uma relação de espécies indicadas para cultivo na Região Centro-Sul, em função das condições edafoclimáticas (CORRÊA JÚNIOR, 1991), além de cravo-da-Índia (Syzygium aromaticum), folhas de goiabeira (Psidium guajava) e laranja (casca) (Citrus sinensis). O material botânico foi fornecido pela Empresa CHAMEL Indústria e Comércio de Produtos Naturais Ltda., produtora e fornecedora de plantas medicinais, exceto camomila, folhas de goiabeira, laranja baiana e marcela, doadas por produtores, e o cravo-daÍndia, adquirido no comércio local. Os extratos aquosos de alecrim, alfavaca, bardana, calêndula, camomila, capim-limão, cavalinha, cravo-da-Índia, espinheirasanta, funcho, gengibre, folhas de goiabeira, hortelã, lípia, quebra-pedra, sabugueiro, tansagem e tagetes foram preparados utilizando-se $10 \mathrm{~g}$ das partes recomendadas das plantas para $100 \mathrm{~mL}$ de meio BDA, numa concentração de $10 \%$, autoclavados durante 20 minutos, a $120^{\circ} \mathrm{C}$ e pressão de $1 \mathrm{~atm}$, em recipientes de vidro, tampados com pedaços de tecido de nylon fixados com elásticos, para posterior filtragem do meio, e com papel alumínio, e vertidos em placas de Petri de 90mm de diâmetro. A testemunha continha apenas BDA.

A extração de óleos essenciais foi realizada em aparelho de CLEVENGER (USP, XXII, 1990), pelo método de hidrodestilação, por arraste com vapor d’água. O tempo de extração foi de 5 horas ininterruptas, após a primeira gota. Os óleos foram armazenados em recipientes de vidro, recobertos por papel alumínio (proteção contra luz), e conservados no freezer. Volumes de $10 \mu \mathrm{L}$ dos óleos essenciais foram depositados em três pontos eqüidistantes de placas de Petri contendo BDA.

Os decoctos (fases aquosas) resultantes da hidrodestilação de alecrim, alfavaca, camomila, capimlimão, funcho, gengibre, folhas de goiabeira, laranja baiana (cascas), lípia, marcela e tagetes foram também utilizados na avaliação do potencial de inibição dos patógenos. O meio de cultura foi preparado utilizandose $90 \mathrm{~mL}$ do decocto e $10 \mathrm{~mL}$ de caldo de batata, preparado com $350 \mathrm{~g}$ de batata para $140 \mathrm{~mL}$ d'água $(10 \mathrm{~mL}$ por tratamento), sendo a quantidade de água reduzida no cozimento para posterior mistura com os decoctos, sendo $2 \mathrm{~g}$ de dextrose e $2 \mathrm{~g}$ de ágar adicionados individualmente. Na testemunha, foi adicionada água destilada.

Discos de $5 \mathrm{~mm}$ de colônias da forma sexuada Glomerella cingulata e assexuada Colletotrichum gloeosporioides, cultivados em BDA, com 15 dias de desenvolvimento, foram repicados, separadamente, para o centro de placas de Petri. O efeito fungitóxico foi avaliado por meio da medida de dois eixos do diâmetro das colônias, quando, no controle em BDA ou em qualquer tratamento, os patógenos atingiram a borda da placa, exceto Colletotrichum gloeosporioides em decoctos.

O delineamento experimental utilizado foi inteiramente casualisado, com três repetições. Os resultados tiveram análise de variância e comparação de médias pelo teste Scott-Knott a 5\% de probabilidade de erro.

\section{RESULTADOS E DISCUSSÃO}

Concomitantemente ao processo de maturação, observou-se o desenvolvimento de lesões características do patógeno Glomerella cingulata (Colletotrichum gloeosporioides) na casca dos frutos de goiabeiras, correspondendo cada lesão a um isolado. Os isolados receberam denominação referente ao número do fruto, cor da polpa vermelha (V) ou branca 
(B) e número da lesão subscrito, sendo os isolados $1 \mathrm{~V}_{1}$ $-2 V_{1}-3 V_{1}-3 V_{2}-3 V_{3}-4 V_{1}$ obtidos de frutos da cultivar "Paluma”, e 1B $\mathrm{B}_{1}-2 \mathrm{~B}_{1}-2 \mathrm{~B}_{2}-2 \mathrm{~B}_{3}-3 \mathrm{~B}_{1}-3 \mathrm{~B}_{2}$ de "Iwao" ou “Carlópolis”. O isolado $2 \mathrm{~V}_{1}$ diferenciou-se dos demais, pela coloração acinzentada do micélio e presença de ascósporos visualizados no microscópio ótico, concluindo tratar-se de Glomerella cingulata, forma sexuada do patógeno. Sintomas característicos foram observados em frutos de polpa vermelha inoculados com os isolados $1 V_{1}-2 V_{1}-3 V_{1}-3 V_{2}-3 V_{3}-4 V_{1}$ e em frutos de polpa branca inoculados com os isolados $1 B_{1}-2 B_{1}-2 B_{2}-2 B_{3}-3 B_{1}-3 B_{2}$, comprovando-se a capacidade dos mesmos, após inoculação causarem a infecção, apesar de frutos de cultivares diferentes encerrarem variações na composição química como teor de açúcar, acidez, dentre outras, que poderiam justificar uma preferência ou especificidade, na relação entre fruto e patógeno. A presença de lesões em todos os frutos de polpa vermelha inoculados com os isolados de polpa branca $\left(1 \mathrm{~B}_{1}-2 \mathrm{~B}_{1}-2 \mathrm{~B}_{2}-2 \mathrm{~B}_{3}-3 \mathrm{~B}_{1}-3 \mathrm{~B}_{2}\right)$ e em todos os frutos de polpa branca inoculados com os isolados de polpa vermelha $\left(1 \mathrm{~V}_{1}-2 \mathrm{~V}_{1}-3 \mathrm{~V}_{1}-3 \mathrm{~V}_{2}-3 \mathrm{~V}_{3}-4 \mathrm{~V}_{1}\right)$ comprovou a inexistência desse fato. Frutos de macieira que foram inoculados com o isolado $2 \mathrm{~V}_{1}$ (Glomerella cingulata) de goiaba apresentaram deterioração da polpa em forma de $\mathrm{V}$ em direção às sementes, sintoma típico da podridão amarga da macieira causada por Glomerella cingulata ou Colletotrichum gloeosporioides, evidenciando-se a ausência de especificidade do isolado de goiaba. Estatisticamente, os isolados $2 \mathrm{~V}_{1}$ (Glomerella cingulata) e $4 \mathrm{~V}_{1}$ (Colletotrichum gloeosporioides) apresentaram-se como os de crescimento mais rápido e foram selecionados para a execução deste estudo.

No metabolismo vegetal, são produzidos metabólitos primários ou macromoléculas, produtos químicos que, através de rotas biossintéticas elaboradas, diversas e freqüentemente desconhecidas, originam os metabólitos secundários ou micromoléculas, geralmente de estrutura complexa, baixo peso molecular, marcantes atividades biológicas e, diferentemente dos metabólitos primários, encontrados em baixas concentrações e em determinados grupos de plantas (Von POSER \& MENTZ, 2000). Produtos do metabolismo primário e secundário, uma vasta gama de compostos orgânicos naturais de origem vegetal são biologicamente ativos, isto é, têm ação: fungicida, inseticida, citotóxica, antiviral, tranqüilizante, analgésica, dentre outras (PLETSCH, 1998). A exploração da atividade biológica de compostos secundários presentes no extrato bruto ou óleo essencial em plantas medicinais pode constituirse em mais uma forma potencial de controle alternativo de doenças de plantas cultivadas, ao lado da indução de resistência (SCHWAN-ESTRADA et al., 2000).

$\mathrm{O}$ extrato aquoso de cravo-da-Índia na concentração de $10 \%$ apresentou efeito fungitóxico inibindo 100\% do crescimento micelial de Glomerella cingulata e Colletotrichum gloeosporioides. Em experimento prévio, o extrato aquoso de cravo-da-Índia na concentração de $1 \%$ apresentou-se igualmente eficiente. Alguns extratos, estatisticamente iguais, não apresentaram efeito inibitório sobre $\boldsymbol{G}$. cingulata (bardana, tansagem, sabugueiro, lípia, espinheirasanta, capim-limão e calêndula) e $\boldsymbol{C}$. gloeosporioides (bardana, tansagem, sabugueiro, cavalinha, alfavaca e hortelã). No extrato de bardana, o crescimento micelial de G. cingulata e $\boldsymbol{C}$. gloeosporioides apresentou-se superior ao controle, assim como, $\boldsymbol{C}$. gloeosporioides nos extratos de tansagem, sabugueiro e hortelã. Extratos aquosos do tecido foliar de duas formas de Lippia alba, utilizados por SANTOS (1996), sobre o crescimento micelial de Colletotrichum gloeosporioides não apresentaram diferenças significativas, quando comparados à testemunha. No controle de Colletotrichum gloeosporioides, agente de podridão em frutos de mamoeiro, o extrato aquoso de folhas de hortelã, incorporado em BDA, a partir da concentração de 200 ppm, demonstrou efeito inibitório (RIBEIRO \& BEDENDO, 1999). Sobre o crescimento micelial de Colletotrichum gloeosporioides, Lasiodiplodia theobromae e Macrophomina phaseolina, responsáveis por expressivas fitomoléstias no Nordeste do Brasil, o extrato das folhas frescas de alfavaca (Ocimum basilicum L.) a 20\%, extraído em solução hidroalcoólica, ocasionou inibição de 100, 91 e $84 \%$, respectivamente, sendo os extratos das folhas secas (5, 10, 15 e 20\%) completamente inativos nas mesmas condições (SILVA et al., 2006). Os demais extratos apresentaram diferenças significativas quando comparados ao controle. O efeito inibitório observado nos extratos de alecrim e gengibre sobre o crescimento micelial de $\boldsymbol{G}$ cingulata e $\boldsymbol{C}$. gloeosporioides e dos extratos de camomila e alfavaca sobre $\boldsymbol{C}$. gloeosporioides indicam potencial de controle da antracnose em frutos de goiabeira.

Utilizados na forma de decoctos, para o controle de Glomerella cingulata, aos sete dias, funcho, alfavaca, marcela, capim-limão, folhas de goiabeira, lípia, tagetes e camomila não diferiram estatisticamente do controle. O mesmo fato foi observado no controle de Colletotrichum gloeosporioides, aos sete dias, com os decoctos de alfavaca , capim-limão, funcho, folhas de goiabeira e lípia. Constatou-se que, na presença do decocto de 
camomila, ocorreu crescimento micelial de $\boldsymbol{G}$ cingulata superior ao controle. Esse fato também foi observado em C. gloeosporioides, com os decoctos de alfavaca, capim-limão e funcho. Os decoctos de alecrim, gengibre, calêndula e laranja baiana (casca) demonstraram potencial de inibição sobre os isolados do patógeno. No controle de $\boldsymbol{C}$. gloeosporioides, destacaram-se também os decoctos de marcela, camomila e tagetes (Tabela 1).

Mediante os resultados obtidos, foi comprovada a existência de compostos secundários biologicamente ativos com efeito fungitóxico, mesmo após aquecimento durante seis horas, sobre o crescimento micelial de Glomerella cingulata e Colletotrichum gloeosporioides, apesar de a decocção ser considerada uma técnica de emprego restrito, devido à alteração de muitas substâncias ativas pelo aquecimento prolongado, e mais empregada em materiais vegetais duros e de natureza lenhosa (FALKENBERG et al., 2000).

É importante salientar que a utilização de uma planta medicinal é tão complexa quanto a sua composição, pois, do cultivo à comercialização, alterações consideráveis podem ocorrer, comprometendo a qualidade e a quantidade dos princípios ativos (MING, 1994). A concentração de princípios ativos não se apresenta uniforme durante o ciclo de vida da planta, variando com o habitat, a colheita e a preparação (TESKE \& TRENTINI 1997), sendo fundamental a observação de fatores como procedência, identificação botânica, colheita (estágio de desenvolvimento da planta, época e horário de coleta), tratamentos fitossanitários e qualidade (MING, 1994).Assim, além dos fatores acima citados, a forma de aproveitamento do material vegetal (seco ou fresco), os métodos de extração, bem como as concentrações utilizadas, resultarão em maior eficiência e credibilidade dos resultados.

$\mathrm{Na}$ natureza, a difusão de traços de compostos voláteis pode induzir ou inibir a germinação ou o crescimento, ou desencadear alterações no desenvolvimento em plantas e fungos (FRENCH, 1992). Os óleos voláteis, óleos essenciais, óleos etéreos ou

Tabela 1 - Crescimento micelial de Glomerella cingulata e Colletotrichum gloeosporioides em meio BDA, in vitro, contendo extratos aquosos, a $10 \%$, e decoctos de plantas medicinais e aromáticas.

Crescimento micelial em cm de

\begin{tabular}{|c|c|c|c|c|}
\hline \multirow{3}{*}{ Tratamentos } & \multicolumn{2}{|c|}{ Glomerella cingulata } & \multicolumn{2}{|c|}{ Colletotrichum gloeosporioides } \\
\hline & Extratos aquosos & Decoctos & Extratos aquosos & Decoctos \\
\hline & 7 dias & 7 dias & 9 dias & 7 dias \\
\hline Testemunha (BDA) & 8,5 a & $9,0 \mathrm{a}$ & $8,7 \mathrm{a}$ & $7,0 \mathrm{a}$ \\
\hline Bardana & 9,0 a & - & 8,9 a & - \\
\hline Tansagem & 8,0 a & - & 9,0 a & - \\
\hline Sabugueiro & 7,9 a & - & 8,8 a & - \\
\hline Lípia & 7,6 a & 9,0 a & $7,8 \mathrm{~b}$ & 6,7 a \\
\hline Espinheira-santa & $7,5 \mathrm{a}$ & - & $8,0 \mathrm{~b}$ & - \\
\hline Capim-limão & 7,4 a & 9,0 a & $6,6 \mathrm{c}$ & $7,7 \mathrm{a}$ \\
\hline Calêndula & 7,2 a & $6,1 \mathrm{~b}$ & $7,6 \mathrm{~b}$ & $5,4 \mathrm{~b}$ \\
\hline Cavalinha & $6,9 \mathrm{~b}$ & - & 8,6 a & - \\
\hline Folhas de goiabeira & $6,7 \mathrm{~b}$ & 9,0 a & $8,2 \mathrm{~b}$ & 6,8 a \\
\hline Tagetes & $6,6 \mathrm{~b}$ & $9,0 \mathrm{a}$ & $7,8 \mathrm{~b}$ & $6,0 \mathrm{~b}$ \\
\hline Funcho & $6,5 \mathrm{~b}$ & 7,5 a & $7,8 \mathrm{~b}$ & $7,5 \mathrm{a}$ \\
\hline Alfavaca & $6,3 \mathrm{~b}$ & $7,5 \mathrm{a}$ & $8,4 \mathrm{a}$ & $7,2 \mathrm{a}$ \\
\hline Quebra-pedra & $6,2 \mathrm{~b}$ & - & $8,1 \mathrm{~b}$ & - \\
\hline Hortelã & $6,1 \mathrm{~b}$ & - & 8,8 a & - \\
\hline Camomila & $5,6 \mathrm{~b}$ & 8,4 a & $6,4 \mathrm{c}$ & $5,0 \mathrm{~b}$ \\
\hline Gengibre & $4,2 \mathrm{c}$ & $6,0 \mathrm{~b}$ & $5,6 \mathrm{~d}$ & $5,7 \mathrm{~b}$ \\
\hline Alecrim & $3,0 \mathrm{c}$ & $5,5 \mathrm{~b}$ & $4,4 \mathrm{e}$ & $4,0 \mathrm{~b}$ \\
\hline Cravo-da-Índia & $0,0 \mathrm{~d}$ & - & $0,0 \mathrm{f}$ & - \\
\hline Laranja baiana (casca) & - & $6,4 \mathrm{~b}$ & - & $5,2 \mathrm{~b}$ \\
\hline Marcela & - & 7,9 a & - & $5,6 \mathrm{~b}$ \\
\hline Média geral & 6,4 & 7,7 & 7,3 & 6,1 \\
\hline CV (\%) & 15,0 & 13,7 & 8,1 & 15,0 \\
\hline
\end{tabular}

Médias não seguidas pela mesma letra diferem estatisticamente pelo teste Scott-Knott a 5\% de probabilidade de erro.

Ciência Rural, v.38, n.2, mar-abr, 2008. 
essências são misturas complexas de substâncias voláteis, lipofílicas, geralmente odoríferas e líquidas, solúveis em solventes orgânicos apolares como éter, porém em água apresentam solubilidade limitada (SIMÕES \& SPITZER, 2000).

Para a avaliação do efeito de óleos essenciais sobre o crescimento de Glomerella cingulata e Colletotrichum gloeosporioides, in vitro, optou-se pela metodologia da distribuição de alíquotas de óleo essencial em três pontos eqüidistantes da placa, pois, segundo JANSSEN, citado por SIANI (2000), a complexidade, a insolubilidade (em água) e a volatilização dificultam a avaliação da atividade antimicrobiana destes.

Os óleos essenciais de cravo e capim-limão inibiram totalmente o patógeno Colletotrichum gloeosporioides (Tabela 2). Com base em porcentagens de inibição, foi observada redução do efeito fungitóxico dos óleos essenciais de alfavaca de $52,0 \%$ para $24,7 \%$, funcho de $84,8 \%$ para $20,9 \%$ e lípia de $69,3 \%$ para $25,9 \%$ sobre o crescimento micelial de Glomerella cingulata do terceiro ao oitavo dia; e dos óleos de alfavaca de $88,8 \%$ para $54,8 \%$, funcho de $93,3 \%$ para $60,9 \%$, gengibre de $92,7 \%$ para $61,1 \%$ lípia de $70,8 \%$ para $15,7 \%$ e tagetes de $54,4 \%$ para $16,9 \%$ sobre Colletotrichum gloeosporioides do terceiro ao décimo dia. O óleo essencial de capim-limão inibiu em 100\% Glomerella cingulata até o quinto dia, apresentando redução no potencial de inibição para $62,8 \%$ no oitavo dia.
Contrariamente, houve aumento no potencial de inibição de Glomerella cingulata e Colletotrichum gloeosporiodes na presença dos óleos de folhas de goiabeira de $10,7 \%$ para $12,4 \%$ e marcela de $25,0 \%$ para $38,0 \%$. A redução do potencial de inibição pode ser atribuída à volatilização dos constituintes dos óleos e/ ou à instabilidade na presença de ar, luz, calor, umidade e metais (SIMÕES \& SPITZER, 2000), modificando a atmosfera no interior das placas de Petri. Halos de inibição formaram-se, quando ocorreu o contato de Glomerella cingulata com os óleos essenciais de camomila, gengibre e folhas de goiabeira e de Colletotrichum gloeosporioides com camomila, goiaba e tagetes, provavelmente devido à presença de compostos fixos com ação fungitóxica.

\section{CONCLUSÃO}

A inibição total ou parcial do crescimento micelial de Glomerella cingulata e Colletotrichum gloeosporioides, in vitro, evidenciou a existência de compostos biologicamente ativos, com efeito fungitóxico, na maioria plantas medicinais e aromáticas utilizadas na forma de extratos aquosos, decoctos e óleos essenciais. Isto indica uma aplicação potencial no controle alternativo da antracnose em frutos de goiabeira.

Tabela 2 - Crescimento micelial de Glomerella cingulata e Colletotrichum gloeosporioides em meio BDA, in vitro, contendo óleos essenciais de plantas medicinais e aromáticas.

Crescimento micelial em cm de

\begin{tabular}{lllllll} 
& \multicolumn{3}{c}{ Glomerella cingulata } & \multicolumn{3}{c}{ Colletotrichum gloeosporioides } \\
\cline { 2 - 7 } & 3 dias & 5 dias & 8 dias & 3 dias & 5 dias & 10 dias \\
\hline Testemunha (BDA) & $4,1 \mathrm{a}$ & $6,3 \mathrm{a}$ & $8,7 \mathrm{a}$ & $3,0 \mathrm{a}$ & $5,2 \mathrm{a}$ & $8,3 \mathrm{a}$ \\
Folhas de goiabeira & $3,6 \mathrm{a}$ & $5,6 \mathrm{~b}$ & $7,9 \mathrm{a}$ & $2,4 \mathrm{~b}$ & $4,1 \mathrm{~b}$ & $7,7 \mathrm{a}$ \\
Laranja baiana (casca) & $3,5 \mathrm{a}$ & $5,7 \mathrm{~b}$ & $8,0 \mathrm{a}$ & $1,1 \mathrm{e}$ & $3,5 \mathrm{c}$ & $7,0 \mathrm{a}$ \\
Marcela & $3,3 \mathrm{a}$ & $5,1 \mathrm{~b}$ & $7,4 \mathrm{~b}$ & $2,2 \mathrm{~b}$ & $4,1 \mathrm{~b}$ & $5,4 \mathrm{a}$ \\
Camomila & $2,9 \mathrm{~b}$ & $4,3 \mathrm{c}$ & $6,3 \mathrm{~b}$ & $1,9 \mathrm{~b}$ & $3,2 \mathrm{c}$ & $6,1 \mathrm{a}$ \\
Tagetes & $2,7 \mathrm{~b}$ & $4,4 \mathrm{c}$ & $7,0 \mathrm{~b}$ & $1,3 \mathrm{~d}$ & $3,1 \mathrm{c}$ & $7,4 \mathrm{a}$ \\
Alecrim & $2,5 \mathrm{~b}$ & $4,6 \mathrm{c}$ & $8,1 \mathrm{a}$ & $1,9 \mathrm{c}$ & $4,0 \mathrm{~b}$ & $8,1 \mathrm{a}$ \\
Gengibre & $2,5 \mathrm{~b}$ & $4,7 \mathrm{c}$ & $7,4 \mathrm{~b}$ & $0,2 \mathrm{f}$ & $0,6 \mathrm{~d}$ & $4,0 \mathrm{~b}$ \\
Alfavaca & $2,0 \mathrm{c}$ & $3,6 \mathrm{~d}$ & $6,6 \mathrm{~b}$ & $0,3 \mathrm{f}$ & $1,3 \mathrm{~d}$ & $4,4 \mathrm{~b}$ \\
Lípia & $1,2 \mathrm{~d}$ & $3,1 \mathrm{~d}$ & $6,4 \mathrm{~b}$ & $1,0 \mathrm{e}$ & $2,9 \mathrm{c}$ & $7,3 \mathrm{a}$ \\
Funcho & $0,9 \mathrm{~d}$ & $2,4 \mathrm{e}$ & $6,7 \mathrm{~b}$ & $0,2 \mathrm{f}$ & $1,0 \mathrm{~d}$ & $2,6 \mathrm{~b}$ \\
Capim-limão & $0,0 \mathrm{e}$ & $0,0 \mathrm{f}$ & $3,1 \mathrm{c}$ & $0,0 \mathrm{f}$ & $0,0 \mathrm{e}$ & $0,0 \mathrm{c}$ \\
Cravo-da-Índia & $0,0 \mathrm{e}$ & $0,0 \mathrm{f}$ & $0,0 \mathrm{~d}$ & $0,0 \mathrm{f}$ & $0,0 \mathrm{e}$ & $0,0 \mathrm{c}$ \\
Média geral & 2,2 & 3,8 & 6,4 & 1,2 & 2,5 & 5,3 \\
CV (\%) & 17,9 & 10,1 & 12,8 & 19,8 & 21,9 & 29,7 \\
\hline
\end{tabular}

Médias não seguidas pela mesma letra diferem estatisticamente pelo teste Scott-Knott a 5\% de probabilidade de erro. 


\section{REFERÊNCIAS}

ALMEIDA, J.G.F. Barreira às exportações de frutas tropicais. Fitopatologia Brasileira, v.27, supl, p.S7-S10, 2002.

BASTOS, C.N.; ALBUQUERQUE, P.S.B. Efeito do óleo de Piper aduncum no controle em pós-colheita de Colletotrichum musae em banana. Fitopatologia Brasileira, v.29, n.5, p.555557, 2004.

Boletim IOBC/WPRS, 1999. In: ANDRIGUETO, J.R.; KOSOSKI, A.R. Marco legal da produção integrada de frutas do Brasil, Brasília: MAPA/SARC, 2002. p.3.

BONALDO, S.M. et al. Fungitoxicity, phytoalexins elicitor activity and protection of cucumber against Colletotrichum Iagenarium, by Eucalyptus citriodora aqueous extract. Fitopatologia Brasileira, v.29, n.2, p.128-134, 2004

CARVALHO, V.D. de. Qualidade e conservação pós-colheita de goiabas. Informe Agropecuário, v.17, n.179, p.48-54, 1994.

CEAGESP. Centro de Qualidade em Horticultura. Classificação da goiaba (Psidium guajava L.). São Paulo, 2000. Fôlder. (Programa Brasileiro para a Melhoria dos Padrões Comerciais e Embalagens de Hortigranjeiros).

CORRÊA JÚNIOR, C. et al. Cultivo de plantas medicinais, condimentares e aromáticas. Curitiba: EMATER-Paraná, 1991. p.151.

CUNICO, M.M. et al. Avaliação antifúngica de extratos obtidos de Ottonia martiana Miq. (Piperaceae) sobre três fitopatógenos. Arquivo Instituto Biológico, Sv.71, supl, p.1-749, 2004.

FALKENBERG, M.B. et al. Introdução à análise fitoquímica. In: SIMÕES, C.M.O. et al. Farmacognosia: da planta ao medicamento. Porto Alegre/Florianópolis: UFRGS/UFSC, 2000. Cap.10.

FRENCH, R.C. Volatile chemical germination stimulators of rust and other fungal spores. Mycologia, v.84, n.3, p.277288, 1992.

FRUPEX. Goiaba para exportação: procedimentos de colheita e pós-colheita. Brasília, DF: Ministério da Agricultura, Abastecimento e Reforma Agrária/ Secretaria De Desenvolvimento Rural - SDR. Programa de Apoio à Produção e Exportação de Frutas, Hortaliças, Flores e Plantas Ornamentais - FRUPEX. Embrapa - SPI, 1996. 35p. il.

KIMATI, H. Controle químico. In: BERGAMIN FILHO, et al. Manual de fitopatologia: princípios e conceitos. 3.ed. São Paulo: Agronômica Ceres, 1995. v.1, 919p.

MING, L.C. Estudo e pesquisa de plantas medicinais na agronomia. Horticultura Brasileira, v.12, n.1, p.2-9, 1994.

NAKA, J. Produção integrada da fruticultura. In: Agroverde Informe - CLAES. Capturado em 20 jun. 2001. Online. Disponível na Internet: http://www.ambiental.net/ agroverde/Produc\%20Integrada\%20Frutas.htm

PLETSCH, M. Compostos naturais biologicamente ativos. A aplicação da biotecnologia à produção de compostos naturais biologicamente ativos. Revista Biotecnologia Ciência \& Desenvolvimento, ano 1, n.4, p.12-15, 1998.

POSER, G.L. Von; MENTZ, L.A. Diversidade biológica e sistemas de classificação. In: SIMÕES, C.M.O. et al. Farmacognosia: da planta ao medicamento. Porto Alegre/ Florianópolis: UFRGS/UFSC, 2000. Cap.4.

RIBEIRO, L.F.; BEDENDO, I.P. Efeito inibitório de extratos vegetais sobre Colletotrichum gloeosporioides - agente causal da podridão de frutos de mamoeiro. Scientia Agricola, v.56, n.4, Supl, p.1267-1271, 1999.

SALGADO, A.P.S.P. et al. Avaliação da atividade fungitóxica de óleos essenciais de folhas de Eucalyptus sobre Fusarium oxysporum,Botrytis cinerea e Bipolaris sorokiniana. Ciência Agrotécnica, v.27, n.2, p.249-254, 2003.

SALUNKHE, D.K.; KADAM, S.S. Handbook of fruit science and technology: production, composition, storage, and processing. New York; Marcel Dekker, 1995. 611p.

SANTOS, M.F.B. dos. Efeito de extratos de duas formas de Lippia alba sobre o fungo Colletotichum gloeosporioides (PENZ.) isolado de Citrus sp. 1996. 105f. Dissertação (Mestrado em Fisiologia e Bioquímica de Plantas) - Escola Superior de Agricultura "Luiz de Queiroz”, Universidade de São Paulo. Piracicaba.

SCHWAN-ESTRADA, K.R.F. et al. Uso de extratos vegetais no controle de fungos fitopatogênicos. Floresta, v.30, n.1 / 2, p.129-137, 2000.

SEBRAEMG. FRUTICULTURA. Considerações sobre o mercado externo. Capturado em 20 jun. 2001. Online. Disponível na Internet: http://www.sebraemg.com.br/arquivos/ programaseprojetos/agronegocios/Fruticultura/Cap4.doc.

SIANI, A.C. et al. Óleos essenciais - Potencial anti-inflamatório. Revista Biotecnologia Ciência \& Desenvolvimento, ano 3, n.16, p.38-43, 2000.

SILVA, M.G. de V. et al. Estudo da composição química dos óleos essenciais obtidos através de várias técnicas e avaliação da atividade antifúngica de Ocimum basilicum. Capturado em 12 mar. 2006. Online. Disponível na Internet: http://www.sbq.org.br/ranteriores/23/resumos/1446-1/ index.html.

SIMÕES, C.M.O.; SPITZER, V. Óleos voláteis. In: SIMÕES, C.M.O. et al. Farmacognosia: da planta ao medicamento. Porto Alegre/Florianópolis: UFRGS/UFSC, 2000. Cap.18.

STANGARLIN, J.R. et al. Plantas medicinais e controle alternativo de fitopatógenos. Revista Biotecnologia Ciência \& Desenvolvimento, ano 2, n.11, p.16-21, 1999.

TESKE, M.; TRENTINI, A.M.M. Herbarium compêndio de fitoterapia. 3.ed. Curitiba: Herbarium Laboratório Botânico, 1997. 317p.

USP, XXII, 1990 THE UNITED STATES PHARMACOPOEIA. 22.ed. Rockville: United States Pharmacopoeial Convention, 1990. 482p. 